\title{
Transgressões no campo da Ciência da Informação: abordagens de uma prática científica em permanente constituição
}

\author{
Meri Nadia Marques Gerlin \\ Doutora; Universidade Federal do Espírito Santo, Vitória, ES, Brasil; \\ merinadia@hotmail.com \\ Elmira Luzia Melo Soares Simeão \\ Doutora; Universidade de Brasília, Brasília, DF, Brasil; \\ elmirasimeao@gmail.com
}

\begin{abstract}
Resumo: O estudo apresenta conceitos ligados à disciplinaridade no campo da Ciência da Informação, assim como, inicia uma discussão em torno da natureza interdisciplinar dessa ciência atravessada pela transgressão metodológica. Reflete sobre a capacidade de interação com outras disciplinas que a atravessam, buscando, com isso, obter soluções de problemas perante a composição de seu objeto: a informação. Para tanto, dialoga-se com autores como Le Coadic, Bicalho e Oliveira, Francelin, Japiassú, Marques, Morin, Pinheiro, Tálamo e Smit. Considera-se que compreender como se deram as transgressões disciplinares no campo da Ciência da Informação torna-se condição essencial para dar conta de pensar a relação inter, multi e, principalmente, transdisciplinar necessária à manutenção de uma prática científica em permanente constituição.
\end{abstract}

Palavras-chave: Ciência da Informação. Interdisciplinaridade. Transdiciplinaridade. Transgressão disciplinar.

\section{Introdução}

A Ciência Moderna inaugurou um novo modo de obter e produzir conhecimento, sendo fortalecida no bojo das transformações sociais e econômicas por volta do século XVII. Como resultado da ligação do empirismo de inventores guiados pela racionalidade de filósofos como Galileu Galilei, Francis Bacon e René Descartes, a nova lógica científica representa um modelo totalitário, negando o caráter racional a todas as formas de conhecimento que não fossem pautados pelos seus princípios epistemológicos e regras metodológicas (BICALHO; OLIVEIRA, 2005; SANTOS, 2010).

As bases da ciência moderna assentam-se nas obras de Copérnico, Kepler, Galileu, Descartes e Newton, entre outros. O método experimental desses pensadores, aliado ao pensamento matemático, constituiu-se em critério de validação da verdade. A natureza perde 
assim a força prescritiva que até então exercia sobre a consciência ética e política dos homens, passando a ser concebida como algo uniforme e quantificável, um fenômeno mecânico. (BICALHO; OLIVEIRA, 2005, p. 2).

A Ciência Moderna é caracterizada por duas concepções antagônicas, "[...] a primeira sujeita ao jugo positivista, a segunda liberta dele, e qualquer delas reivindicando o monopólio do conhecimento científico-social." (SANTOS, 2010, p. 34). A primeira, marcada pelo compromisso epistemológico simbolizado pelo nome de física social, parte do pressuposto de que as ciências naturais são uma aplicação ou concretização de um modelo de conhecimento universalmente válido. Já a segunda concepção reivindica, para as ciências sociais, um estatuto metodológico próprio, no qual os obstáculos podem ser considerados como intransponíveis. O argumento fundamental que se apresenta é que a ação humana é subjetiva e, por conseguinte, "O comportamento humano, ao contrário dos fenômenos naturais, não pode ser descrito e muito menos explicado com base nas suas características exteriores e objetiváveis [...]” (SANTOS, 2010, p. 38).

Devido às ciências sociais, em alguns momentos, se voltar para aspectos fortemente relacionados à subjetividade, torna-se importante pensar na utilização de métodos de investigação e critérios epistemológicos diferentes daqueles que são utilizados nas ciências naturais. Da mesma forma, às vezes, faz-se necessário considerar "[...] métodos qualitativos em vez de quantitativos, com vista à obtenção de um conhecimento intersubjetivo, descritivo e compreensivo, em vez de um conhecimento objetivo, explicativo e nomotético.” (SANTOS, 2010, p. 38).

As duas concepções pertencem ao paradigma da Ciência Moderna, ainda que a segunda represente um sinal de crise e contenha alguns dos componentes da transição para outro paradigma científico ${ }^{1}$. A crise anunciada no cerne da Ciência Moderna, denominada crise do paradigma dominante, representa um desenho emergente considerado não apenas no âmbito científico (o paradigma de uma vida prudente), mas também como um paradigma social (o paradigma de uma vida decente) (SANTOS, 2010). 
Essa discussão surge da necessidade de superação da dicotomia entre ciências naturais e ciências sociais. No entanto, a constituição do paradigma emergente está diretamente vinculada ao rompimento com a epistemologia e a metodologia positivista imposta pelas ciências naturais. Assim sendo, recorre-se a uma concepção humanística das ciências sociais que, ao contrário do pensamento das humanidades tradicionais, apresenta o indivíduo como autor e sujeito do mundo social em que vive e, diretamente, interfere.

$\mathrm{Na}$ atualidade, a ciência pode ser definida como um conjunto de ferramentas, métodos, procedimentos, conceitos e teorias que tentam explicar objetos e/ou assuntos de uma variedade de pesquisas, tendo em vista as contingências externas da sociedade e da comunidade científica (BICALHO; OLIVEIRA, 2011). As disciplinas das ciências naturais e humanas devem ser mobilizadas de forma que possam convergir para questões sociais, podendo, assim, atender as demandas que, constantemente, surgem no contexto atual da sociedade (MORIN, 2003).

O estabelecimento de um novo parâmetro de conhecimento científico, estabelecido a partir da segunda metade do século $\mathrm{XX}$, não nega o valor da ciência clássica, tampouco concorre com ela. A revolução iniciada que transforma e gera novas fronteiras para a ciência contemporânea, possibilita o questionamento de ideias fundamentais que provocam alterações no paradigma científico moderno (MORIN, 2003). Na Ciência Moderna, o conhecimento avança pela especialização e pela caracterização monodisciplinar, com expressiva demarcação das fronteiras entre as disciplinas.

A organização disciplinar foi instituída no século XIX, notadamente com a formação das universidades modernas; desenvolveu-se depois, no século XX, com o impulso dado à pesquisa científica; isto significa que as disciplinas têm uma história: nascimento, institucionalização, evolução, esgotamento etc; essa história está inscrita na Universidade, que, por sua vez, está inscrita na história da sociedade; daí resulta que as disciplinas nascem da sociologia das ciências e da sociologia do conhecimento. Portanto, a disciplina nasce não apenas de um conhecimento e de uma reflexão interna sobre si mesma, mas também de um conhecimento externo. Não basta, pois, estar por dentro de uma disciplina para conhecer todos os problemas aferentes a ela. (MORIN, 2003, p. 103). 
Segundo Pombo (2005), o problema da especialização encontra os seus limites no momento em que a ciência toma consciência que o todo não é a soma das partes. "É hoje reconhecido que a excessiva parcelização e disciplinarização do saber científico faz do cientista um ignorante especializado. Isso acarreta efeitos negativos, que são sobretudo visíveis no domínio das ciências aplicadas." (SANTOS, 2010, p. 74). A chamada parcelização do conhecimento e reducionismo arbitrário desencadeiam novas disciplinas para resolver os problemas que, muitas vezes, acabam por reproduzir o mesmo modelo de cientificidade.

Ao contrário do que sucede no paradigma dominante, no paradigma emergente, a fragmentação moderna não é disciplinar e sim temática. Tendo em vista que os temas são galerias nas quais os conhecimentos progridem ao encontro uns dos outros, o conhecimento, enfim, pode avançar à medida que seu objeto se amplia. Um conhecimento desse tipo constitui-se a partir de uma pluralidade metodológica.

Só uma constelação de métodos pode captar o silêncio que persiste entre cada língua que pergunta. Numa fase de revolução científica como a que atravessamos, essa pluralidade de métodos só é possível mediante transgressão metodológica. (SANTOS, 2010, p. 78).

A abertura para o crescimento de uma diversidade de metodologias, a capacidade de aquisição da informação e a produção de conhecimento científico trazidos pela modernidade apontam para o fato de que os princípios científicos estão em permanente desenvolvimento, transgredindo ao que está posto. As teorias científicas não são exclusivamente reflexos da realidade objetiva, mas também compõem importantes estruturas das condições sociais e culturais do conhecimento estruturado (MORIN, 2003).

Nas ciências humanas e sociais, de uma forma geral, a interpenetração de conceitos tem sido mais bem aceita, visto que seu objeto de estudo - o homem e suas relações sociais - exige, muitas vezes, a busca de outros domínios a fim de que possa ser apreendido em sua totalidade. Com o crescimento da ciência moderna surgiram novas disciplinas ou áreas de conhecimento como a Ciência da Informação, a Fisioterapia e os estudos do Meio-Ambiente, que fogem ao padrão da ciência clássica, possuindo características que as diferenciam de outras áreas cuja origem é mais remota. Estas disciplinas, já na sua formação, 
foram impelidas a estabelecer interações com outras por tratarem de problemas que exigiam novas formas de tratamento para sua solução, por se situarem em um contexto social, político e econômico totalmente novo, pós-moderno. Daí serem indicadas como áreas em que as práticas interdisciplinares são peculiares a elas como o caminho de desenvolvimento para as suas pesquisas. (BICALHO; OLIVEIRA, 2005, p. 1).

Pombo (2005) expõe que novas situações epistemológicas constituem novos tipos de disciplinas, sendo que algumas acabam nascendo nas fronteiras entre disciplinas tradicionais: "Como exemplos, refiram-se a bioquímica, a biofísica, etc. Outras, como interdisciplinas, aquelas que nascem na confluência entre ciências puras e ciências aplicadas." (POMBO, 2005, p. 10). A Ciência da Informação (CI) é um exemplo do exposto, sendo reconhecida em 1960 como um campo de conhecimento interdisciplinar. A ideia de interdisciplinaridade que atravessa a sua constituição é de cerca de 1840 , refletindo-se como um desafio enfrentado na atualidade (PINHEIRO, 2007).

Le Coadic (2004) contextualiza que a CI é de origem anglo-saxônica, nascendo com a contribuição de disciplinas como a Biblioteconomia e a Documentação. Para esse autor, a Informação é o objeto dessa ciência, podendo ser definida como conhecimento inscrito (registrado) em forma escrita (impressa ou digital), oral ou audiovisual. Constituindo-se como uma área interdisciplinar, acaba sendo determinada por condições históricas e socioeconômicas e, por conseguinte, pelo advento da eletrônica/ informática, o que reforça as tendências de armazenamento de enormes volumes de informação na sociedade da informação para possibilitar o seu uso efetivo. Desde sua criação, depara-se com obstáculos insuperáveis nas inúmeras tentativas de reconhecer seu objeto.

[...] porque, de um lado, supõe-se encontrá-lo perfeitamente identificado no mundo e, de outro, espera-se obter uma definição dele que seja universal e discriminante. Assim, recorre-se simultaneamente à simplificação e à naturalização a que conduz a razão moderna, reafirmando-se que o objeto do campo é a informação. (TÁLAMO; SMIT, 2007a, p. 29-30).

Se a caracterização da CI deve ser buscada em uma abordagem informacional do mundo, então, aquilo que constantemente é denominado de objeto, para alguns autores, torna-se um ponto de vista ao qual recorrem 
diversos pesquisadores, para a problematização dos elementos no mundo com relevância social.

Outra possibilidade [de diálogo], que não seja puro reducionismo, consiste em observar como no passado os domínios que estão na origem da Ciência da Informação organizaram-se. Tomemos apenas dois: a Biblioteconomia Moderna marcada pelo pensamento de M. Dewey e a Documentação proposta por P. Otlet. Em comum, ambos protagonizam a aplicação como mote de sua atividade: organiza-se a coleção para a prestação de serviço do mesmo modo que se organizam os conteúdos para recuperação do documento. Traduzidas para o presente momento, tais concepções evidenciam que os conceitos "coleção", "documento" e "recuperação" expressam o modo pelo qual cada um dos campos problematiza a questão da informação nos contextos em que se inseriam os respectivos autores. Não se tem, portanto, um objeto no sentido tradicional. (TÁLAMO; SMIT, 2007b, p. 40).

Ao considerar, por exemplo, a recuperação da informação como o objetivo do processo documentário, a informação não é apresentada como objeto e, sim, como um ponto de vista adotado, a fim de analisar os processos e objetos no contexto da CI. A importância da abordagem da noção de objeto para a ciência, por mais universal que seja, não se limita apenas a uma definição exata. O objeto de pesquisa que é apresentado por Le Coadic (2004) é a base para desenvolvimento de todo conhecimento, e o termo é usado na Administração, Biologia, Ciência da Computação, Comunicação Social e outras disciplinas, com visões e usos de diferenciados contextos. Então, qualquer que seja a abordagem, a fluidez do conceito de informação é sempre uma dificuldade para que essa ciência construa um domínio sólido, refletindo certa ambiguidade, o que, segundo Tálamo e Smit (2007a; 2007b), acaba por construir uma diversidade de "ponto de vista".

O objeto de estudo dessa ciência - a informação - acaba constituindo-se como um fenômeno que está relacionado a todos os campos do conhecimento científico. Faz-se necessário enfocar possíveis inter-relações e possibilidades de intervenção, não apenas com os campos de pesquisa, mas também com a sociedade acadêmica científica e sociedade externa a esse processo (FREIRE, 2006). Para superar dificuldades conceituais advindas das múltiplas facetas próprias ao seu objeto de estudo, esse campo de atuação deve buscar a construção de uma rede conceitual, tecida a partir do olhar das várias disciplinas 
e áreas com as quais se relaciona. Nesse momento, entender a trans e interdisciplinaridade como uma exigência imanente permite pensá-la como uma forma de organização do mundo feita coletivamente.

O entendimento dessa ciência como campo teórico e científico aparece marcado pela ausência de um modelo de origem consistente que lhe confira identidade. A colocação de que o estabelecimento de relações entre as disciplinas é o aspecto que mais identifica essa ciência, podendo conduzir essa reflexão a algumas vertentes ligadas tanto ao fortalecimento quanto ao enfraquecimento, dependendo do tecido da discussão metodológica. O debate sobre a natureza da CI acontece desde a sua criação enquanto disciplina.

A indispensável necessidade para fazer a ponte entre as diferentes disciplinas é atestada pela emergência da pluridisciplinaridade e da interdisciplinaridade por volta do meado do século 20 , sendo que ainda temos a multidisciplinaridade (ou seja, disciplinas que se ancoram uma nas outras) e transdisciplinaridade [...] (SOUZA, 2007).

Interessa, então, saber se essa discussão indica caminhos de relevância social pela via das transgressões disciplinares no campo da CI, ao envolver no diálogo disciplinas como Biblioteconomia, Arquivologia, Documentação e outras áreas do saber. Da característica do pensamento monodisciplinar à transgressão metodológica destacam-se conceitos ligados à disciplinaridade no campo da CI que não se encerram nela. Nesse sentido, procura-se discutir a natureza interdisciplinar dessa ciência atravessada pela transgressão e reflete-se a capacidade de interação que essa ciência apresenta com outras disciplinas, para assim obter a solução de problemas perante seu objeto ${ }^{2}$. Para tanto, realizase uma revisão de literatura ao dialogar com pesquisadores como Le Coadic (2004), Bicalho e Oliveira (2011), Francelin (2012), Japiassú (2001), Marques (2015), Morin (2003), Pinheiro (1999), Tálamo e Smit (2007).

\section{Multi, pluri, trans e interdisciplinaridade: abordagens de uma ciência que não se encerram na disciplinaridade}

Entende-se por disciplina a exploração científica especializada em certa área ou domínio homogêneo de pesquisa/estudo, devendo, “[...] antes de tudo, 
estabelecer e definir fronteiras constituintes. Fronteiras estas que irão determinar seus objetos materiais e formais, seus métodos, sistemas, conceitos e teorias." (JAPIASSÚ, 1976, p. 61).

A discussão sobre as fronteiras entre as ciências e as "fronteiras conceituais" é certamente complexa. O que pode ser retido dessa discussão é que os domínios de pertinência dos conceitos devem ser definidos dentro de fronteiras, não significando, porém, que os campos do saber não se relacionam, ou seja, não ultrapassam as próprias fronteiras que estabelecem. (FRANCELIN, 2012, p. 158).

A disciplina também pode ser entendida como uma categoria do conhecimento científico, instituindo a divisão e a especialização do trabalho e respondendo à diversidade das áreas que as ciências compreendem. Dentro de um contexto mais amplo, tende naturalmente à autonomia pela delimitação das fronteiras, da linguagem, das técnicas elaboradas e utilizadas (MORIN, 2003). A disciplinaridade como organização da ciência em disciplinas, por um lado “[...] delimita um domínio de competência sem o qual o conhecimento torna-se fluido e vago, de outro, ela desvenda, extrai ou constrói um 'objeto' digno de interesse para o estudo científico." (JAPIASSÚ, 1976, p. 40).

[...] a instituição disciplinar acarreta, ao mesmo tempo, um perigo de hiperespecialização do pesquisador e um risco de "coisificação" do objeto estudado, do qual se corre o risco de esquecer que é destacado ou construído. O objeto da disciplina será percebido, então, como uma coisa auto-suficiente; as ligações e solidariedades desse objeto com outros objetos estudados por outras disciplinas serão negligenciadas, assim como as ligações e solidariedades com o universo do qual ele faz parte. A fronteira disciplinar, sua linguagem e seus conceitos próprios vão isolar a disciplina em relação às outras e em relação aos problemas que se sobrepõem às disciplinas. (MORIN, 2003, p. 106).

Algumas críticas são feitas em oposição a uma das características que a fundamenta: a especialização. Japiassú (1976) expõe que, em se tratando do objeto de estudo da ciência, a disciplina converteu o cientista em um sujeito que sabe tudo sobre nada. Por outro lado, outros autores não negam o avanço científico resultante da especialização, no que se refere à solução de inúmeros problemas científicos (BICALHO; OLIVEIRA, 2005). 
Indubitavelmente, a CI como uma disciplina emergente recebeu a contribuição de outras disciplinas com campos especializados em um determinado domínio de estudo. Destacam-se a Biblioteconomia, a Documentação e a Informática que auxiliaram no seu processo de constituição. Como disciplina, esse campo do saber tem o mesmo sentido que ciência.

[...] isto é, o conjunto sistemático e organizado de conhecimentos que apresentam características próprias no plano de ensino, da formação, dos métodos e das matérias; esta exploração consiste em fazer surgir novos conhecimentos que se substituem aos antigos. (JAPIASSÚ, 1976, p. 72).

Conforme as discussões sobre a consolidação do campo disciplinar avançam, cria-se uma maior dificuldade de fundamentar seu campo teórico em um sistema conceitual próprio. Com " [...] um sistema de conceitos encontra sua maior dificuldade no próprio conceito 'Ciência da Informação'. Geralmente, a tentativa em conceituá-lo reaviva, inevitavelmente, as teorias sobre a própria concepção [...]” (FRANCELIN, 2012, p. 160).

Figura 1 - Disciplinaridade no contexto da Ciência da Informação.

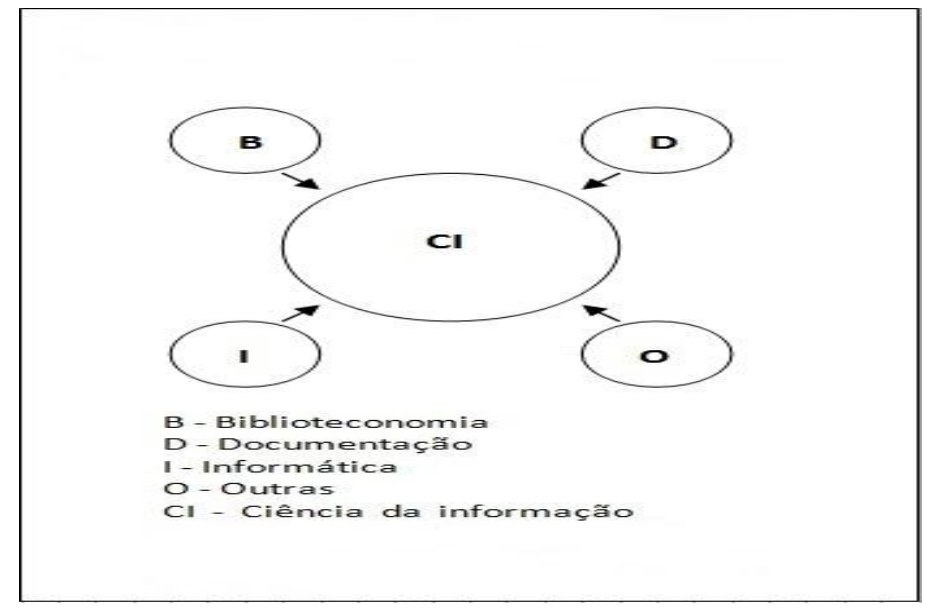

Fonte: Dados da pesquisa.

A CI é fruto da ciência moderna e, portanto, da disciplinaridade; não podendo como uma disciplina manter-se isolada, deve estar sempre dialogando com disciplinas que auxiliaram no processo de sua constituição e com outras que produzem ciência (Biblioteconomia, Documentação, Informática e outras) 
(Figura 1). As disciplinas ao entorno da CI têm fronteiras definidas, mas não se pode negar a necessidade de um diálogo mais intenso entre elas. Existem "[...] questões complexas que não podem ser tratadas a contento de forma monodisciplinar. Daí o desafio de religar elementos comuns de diferentes disciplinas para tratar de assuntos pertencentes a cada uma, sob diferentes ângulos.” (BICALHO; OLIVEIRA, 2005, p. 3).

Outras abordagens coexistem com os saberes disciplinares, representando o início de transgressões necessárias à prática nesse campo de atuação científica. É possível, então, colocar que a constituição do campo da CI por natureza se constituiu

[...] como a interação de duas ou mais disciplinas. Essas interações podem implicar transferência de leis de uma disciplina a outra, originando, em alguns casos, um novo corpo disciplinar. A Ciência da Informação que tem como característica a interdisciplinaridade ao permitir que várias disciplinas interajam é um exemplo disso e esta interação pode ser caracterizada desde uma simples comunicação das ideias até uma integração mútua dos conceitos, da epistemologia, da terminologia, da metodologia, dos procedimentos, dos dados e da organização da pesquisa nessa ciência. (BICALHO; OLIVEIRA, 2005, p. 4).

Pinheiro e Loureiro (1995, p. 10) contextualizam que "Diferentemente do exterior, no Brasil há pouca literatura sobre CI como campo científico.”. O levantamento conceitual elaborado em torno dela confirma que há consenso quanto à interdisciplinaridade dando visibilidade a algumas de suas interfaces que são mais evidenciadas.

Para Japiassú (2001), o objetivo do método interdisciplinar e do desenvolvimento da especialização sem limite das ciências é a unidade do saber. Segundo esse autor, a interdisciplinaridade corresponde a uma nova etapa de desenvolvimento do conhecimento científico, assim como, da divisão epistemológica, exigindo que as disciplinas científicas estejam inseridas em um processo de interpenetração. A interdisciplinaridade não nega as disciplinas, uma vez que está ancorada nelas para o seu desenvolvimento. Dessa forma, entende-se que

[..] a interdisciplinaridade é um método de pesquisa e de ensino suscetível de fazer com que duas ou mais disciplinas interajam entre si. Esta interação pode ir da simples comunicação 
das ideias até a integração mútua dos conceitos, da epistemologia, da terminologia, da metodologia, dos procedimentos, dos dados e da organização da pesquisa. Ela torna possível a complementaridade dos métodos, dos conceitos, das estruturas e dos axiomas sobre os quais se fundam as diversas práticas científicas. (JAPIASSÚ, 2001, p. 106).

Pinheiro (1999, p. 156) expõe que na "[...] interdisciplinaridade há o reconhecimento de que a CI incorpora muito mais contribuições de outras áreas, do que transfere para essas um corpo de conhecimentos gerados dentro de si mesma.". No que diz respeito ao que é produzido pela literatura científica, principalmente, o que toca a interdisciplinaridade, a sua produção acaba por elencar disciplinas com as quais mantém relação. Entretanto, na maioria das vezes, sem o devido aprofundamento ou mesmo uma teoria sólida que a justifique.

Se não existe um corpo conceitual próprio da Ciência da Informação, a busca de soluções para os problemas da área é deslocada para outras disciplinas, levando à importação de conceitos, nem sempre apropriados. Usa-se "apropriados" no duplo sentido do termo, ou seja, nem sempre a Ciência da Informação se apropria de conceitos de outras áreas e lhes dá um sentido próprio, como nem sempre a apropriação é adequada. (FRANCELIN, 2012, p. 160).

A interdisciplinaridade está longe de ser evidente no campo da CI. Presente nos ambientes de produção científica, ligados à pesquisa e à técnica, ainda pode ser relegada ao ostracismo imposto pelo pensamento positivista. A transgressão disciplinar acontece devido a um rompimento com os modelos existentes, apresentando-se como uma exigência imposta pela contemporaneidade e, por conseguinte, como resultado da articulação entre a teoria e uma prática reflexiva (práxis fundamentada no campo da disciplinaridade) (PINHEIRO, 2007).

O esboço dos possíveis campos interdisciplinares possibilita a ideia de que

[...] a característica central da interdisciplinaridade consiste no fato de que ela incorpora os resultados de várias disciplinas, tomando-lhes [assim] de empréstimo esquemas conceituais de análise, a fim de fazê-los integrar depois de havê-los comparado e julgado. (PINHEIRO; LOUREIRO, 1995, p. 14). 
Esse contexto requer que cada especialista transcenda a própria especialidade, tomando consciência dos seus limites, a fim de acolher as contribuições das outras disciplinas.

Figura 2 - Interdisciplinaridade no contexto da Ciência da Informação.

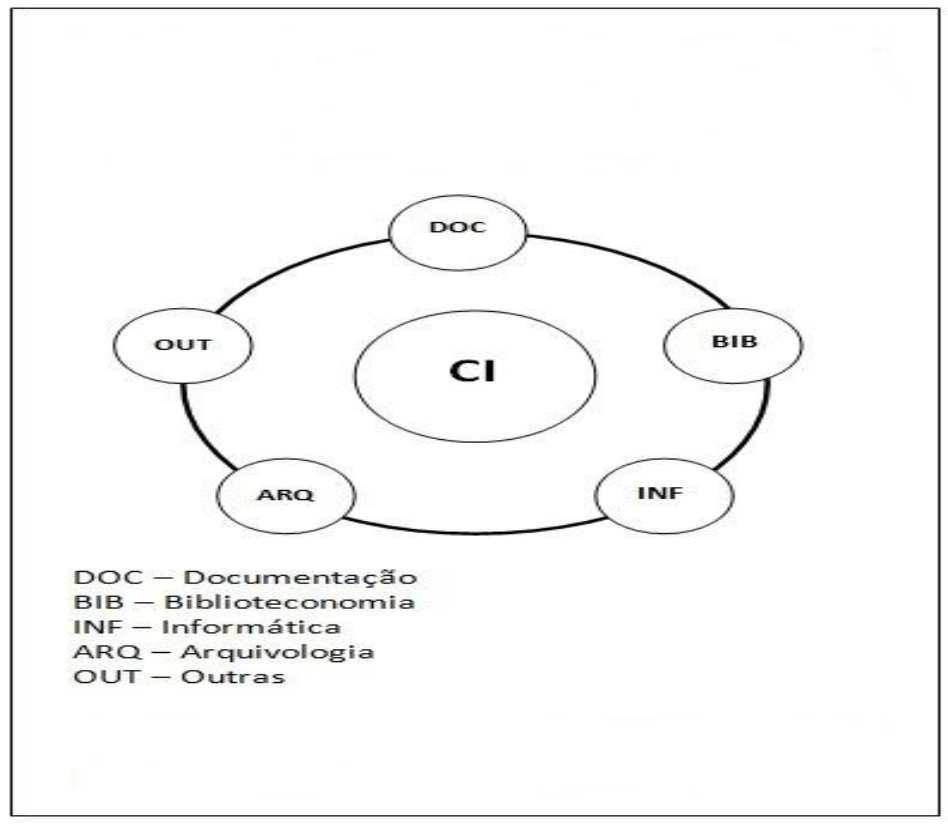

Fonte: Dados da pesquisa.

Uma perspectiva pautada na interdisciplinaridade subentende "diálogo entre disciplinas" e/ou a apropriação mútua de metodologias, princípios, teorias, conceitos e construtos entre duas ou mais disciplinas nesse processo de diálogo, ao adotar uma perspectiva teórica e metodológica comum para as disciplinas envolvidas. Promovendo a integração dos resultados obtidos, e no processo de diálogo, busca a resolução dos problemas por meio da articulação dos saberes entre as disciplinas, preservando o interesse de disciplinas como Documentação, Biblioteconomia, Informática, Arquivologia e outras envolvidas no processo de diálogo (Figura 2).

Gomes (2001, p. 8) expõe que a “[...] interdisciplinaridade efetiva é aquela que se atualiza no campo das abstrações teóricas, do estabelecimento das metodologias, mas também nas intervenções que as disciplinas promovem no meio social.”. Muitas vezes, é examinada apenas a partir da focalização do 
movimento interno de uma disciplina, correndo o risco de se deter apenas na perspectiva teórica.

O termo interdisciplinaridade consiste na ideia de solução dos problemas por meio da interação entre as disciplinas, porém, muito ainda deverá ser discutido sobre essa abordagem. Deve-se, então, pensar nessa abordagem “[...] como uma questão mais ampla, não somente acadêmica, uma vez que suas teorias são também teorias sobre conhecimento e cultura." (PINHEIRO, 2007, p. 73).

A interdisciplinaridade constitui a CI impondo uma necessidade de promover a interação entre campos disciplinares diferentes na solução de problemas específicos. Pombo (2005) contextualiza que não há uma definição precisa e exaustiva em torno da interdisciplinaridade, entretanto, reconhece que por detrás da pluri, multi, inter e transdisciplinaridade existe uma mesma raiz: a disciplina. Nessa direção, essas outras abordagens aparecem como uma transgressão necessária para CI.

Torna-se necessário não confundir a interdisciplinaridade com a multi ou pluridisciplinaridade, o que seria justaposição de duas ou mais disciplinas, com objetivos múltiplos sem relação entre si, com certa cooperação mas sem coordenação num nível superior. (JAPIASSÚ, 2001, p. 106).

A pluridisciplinaridade seria traduzida pela " [...] justaposição de diversas disciplinas situadas geralmente no mesmo nível hierárquico e agrupadas de modo a fazer aparecer relações existentes entre elas.” (JAPIASSÚ, 1976, p. 73 apud PINHEIRO, 2007, p. 74). No momento em que uma enorme gama de disciplinas é proposta simultaneamente, sem fazer aparecer as relações que podem existir entre elas, seria traduzido como multidisciplinaridade.

\footnotetext{
A multidisciplinaridade é uma estratégia que permite a aproximação e a cooperação entre as disciplinas, pelo estabelecimento de diálogos antes inexistentes. Contudo apresenta limitações ao desenvolvimento do conhecimento, uma vez que existe somente uma justaposição de vários tipos de metodologias, com cada campo mantendo sua lógica própria e sua fronteira. (BICALHO; OLIVEIRA, 2005, p. 4).
}

Diferenciando-a do contexto da abordagem da pluridisciplinaridade, Japiassú (1976) apresenta a multidisciplinaridade como uma estratégia que 
permite a aproximação entre as disciplinas propostas simultaneamente. Entretanto, sem que se tenha relações entre elas.

Figura 3 - Multidisciplinaridade no contexto da Ciência da Informação.

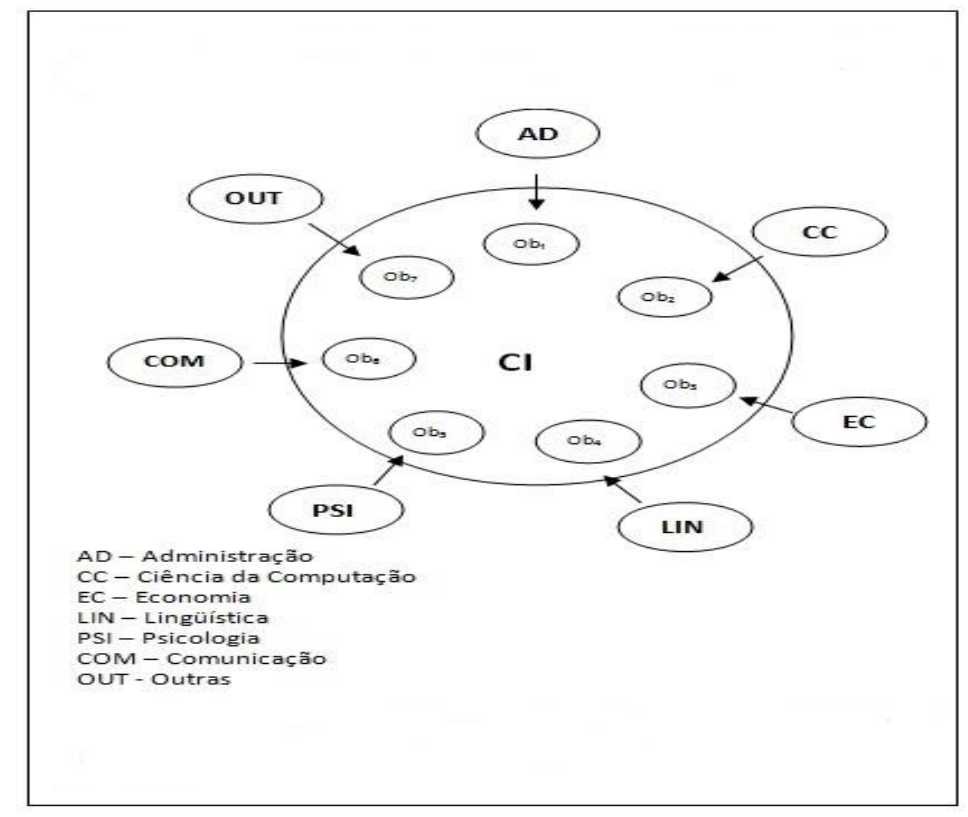

Fonte: Dados da pesquisa.

Se o objeto da CI é resultado do diálogo de diferentes disciplinas e práticas no campo da informação e áreas afins, a abordagem multidisciplinar permite que o objeto dessa ciência seja estudado por várias outras disciplinas ao mesmo tempo: Administração; Ciência da Computação; Economia; Linguística; Psicologia; Comunicação e outras (Figura 3). Para superar as dificuldades, torna-se necessário modificar o formato das interações, para assim, tornar possível que metodologias das diferentes disciplinas possam originar novas disciplinas, imbricadas "[...] em um processo de interação que exige mais abertura à aprendizagem e ao novo.” (BICALHO; OLIVEIRA, 2005, p. 4).

Perante a apresentação do modelo multidisciplinar, a CI aparece como resultado dos saberes de outras disciplinas, como a Documentação, a Biblioteconomia e a Informática, sem, com isso, desconsiderar que recebe a contribuição de outras disciplinas. Todavia, torna-se necessário existir cooperação, o que acaba não acontecendo com a multidisciplinaridade, tampouco com a pluridisciplinaridade que seria um estágio que privilegiaria 
uma complementação entre disciplinas próximas. "A pluridisciplinaridade diz respeito ao estudo de um objeto de uma mesma e única disciplina por várias disciplinas ao mesmo tempo.” (NICOLESCU, 1999, p. 51).

O conhecimento do objeto em sua própria disciplina é aprofundado por uma fecunda contribuição pluridisciplinar. A pesquisa pluridisciplinar traz um algo mais à disciplina em questão (a história da arte ou a filosofia, em nossos exemplos), porém este `algo mais' está a serviço apenas desta mesma disciplina. Em outras palavras, a abordagem pluridisciplinar ultrapassa as disciplinas, mas sua finalidade continua inscrita na estrutura da pesquisa disciplinar. (NICOLESCU, 1999, p. 52).

Apesar das abordagens multi e pluridisciplinar visarem uma resolução de problemas no campo da CI em uma relação de troca de conhecimento científico, ainda não se constituem como uma modificação da base teórica, a fim de causar uma transgressão disciplinar e/ou metodológica que rompa com as estruturas do modelo disciplinar vigente. Por outro lado, a adoção do sufixo trans supõe ir além, uma ultrapassagem daquilo que é próprio da disciplina.

[...] há qualquer coisa que atravessa a pluridisciplinaridade ou multidisciplinaridade, a interdisciplinaridade e a transdisciplinaridade. Que essa qualquer coisa é, em todos os casos, uma tentativa de romper o carácter estanque das disciplinas. Mas que essa tentativa se pode fazer em diferentes níveis, em diferentes graus. (POMBO, 2005, p. 5).

Diante da possibilidade que os autores pesquisados apresentam, ao contextualizar a necessidade de abordagens que consigam propor soluções para problemas complexos no campo da CI, torna-se necessário promover pesquisas que consigam transgredir conhecimentos disciplinares. $\mathrm{O}$ trabalho com $\mathrm{o}$ estabelecimento de espaços de diálogos entre as disciplinas e outros campos do saber deve ser constantemente (re)pensado.

\section{0 contexto transgressor da transdisciplinaridade}

A transdisciplinaridade pode ser caracterizada como uma abordagem que possibilita que as disciplinas e outras áreas do conhecimento estabeleçam diálogos, ao permitir o livre trânsito de um campo do saber para outro. 
Transportar, então, essa perspectiva para o campo da CI significa uma mudança epistemológica e não apenas metodológica.

A transdisciplinaridade, como o prefixo 'trans' indica, diz respeito àquilo que está ao mesmo tempo entre as disciplinas, através das diferentes disciplinas e além de qualquer disciplina. Seu objetivo é a compreensão do mundo presente, para o qual um dos imperativos é a unidade do conhecimento. (NICOLESCU, 1999, p. 52).

Diante desse contexto, destaca-se que a abordagem transdisciplinar ainda está em construção, sendo constantemente discutida no sentido de promover a integração dos saberes e ultrapassar as barreiras disciplinares (BICALHO; OLIVEIRA, 2011). Tendo em vista que o que se propõe é uma superação do modelo disciplinar, essa abordagem representa, então, um nível de integração disciplinar para além das abordagens existentes, não podendo haver nenhuma fronteira que impossibilite a integração entre as disciplinas e outras áreas de atuação. Com a transdiciplinaridade, nenhum saber pode ser considerado mais importante do que o outro no processo de troca, instaurando assim momentos de diálogos.

\begin{abstract}
A transdisciplinaridade pode representar a solução à departamentalização cada vez maior do conhecimento científico, mantendo-se e respeitando-se a contribuição de cada disciplina. Esta reforma, contudo, deve passar pelo entendimento de que a sociedade está em evolução permanente e que deverá ser feito um esforço para entender o todo, contextualizado, evitando-se as dicotomias próprias do paradigma cartesiano. O surgimento de abordagens complementares à disciplinaridade indica que um movimento rumo a um novo paradigma científico está emergindo. (BICALHO; OLIVEIRA, 2005, p. 2).
\end{abstract}

Desse modo, a CI pode dialogar com outras disciplinas e áreas de conhecimento, ao conceber uma articulação de conceitos e metodologias no campo da comunicação, tecnologia e informação, por exemplo (MARQUES, 2015). Esses processos não precisam constituir-se necessariamente com uma disciplina, podendo ser entendidos como uma tentativa de compreender e interagir com as demandas do mundo atual (PINTO, 2007).

Diante de uma perspectiva de trabalho transdisciplinar, as ações, no campo da CI, abrem-se para o contato com outras disciplinas e áreas, ao 
estabelecer trocas efetivas com: as redes sociais, as novas tecnologias, "[ [...] as artes, a literatura, o conhecimento popular, as religiões e Filosofia, buscando mostrar uma nova visão da realidade, percebida além das fronteiras." (PINTO, 2007, p. 113) que as disciplinas impõem. Cabe, então, encontrar outras possibilidades de produção de conhecimentos e de atuação que possibilitem práticas e diálogos para além dos limites das disciplinas que compõem a CI.

A produção de conhecimento, no âmbito da transdisciplinaridade, pode ser considerada como uma práxis transgressora no campo da informação. O diálogo estabelecido em torno dos objetivos e das metas das disciplinas pode se constituir como uma possibilidade de ampliar a aquisição de informação e produção de conhecimento, tanto nas áreas de informação ligadas à CI (como a Arquivologia, a Biblioteconomia e a Documentação) quanto com outras disciplinas: Administração; Ciência da Computação; Economia; Linguística; Psicologia; Comunicação e outras (PINTO, 2007) (Figura 4).

Figura 4 - Transdiciplinaridade no contexto da Ciência da Informação.

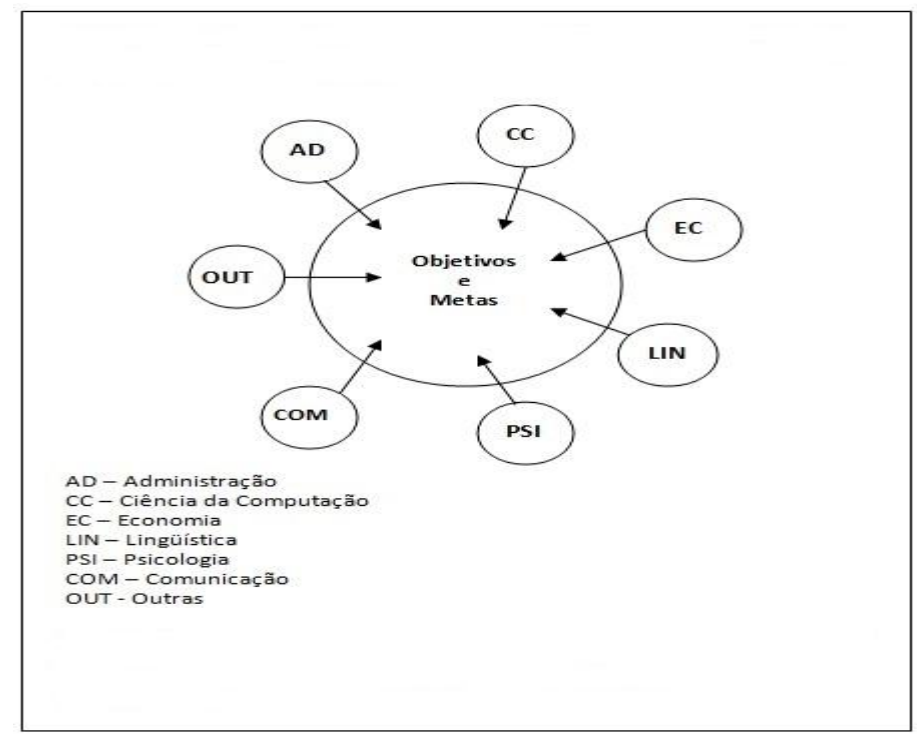

Fonte: Dados da pesquisa.

Um diálogo no contexto da CI que transita em campos disciplinares como Comunicação e Computação proporciona “[...] múltiplos pontos de observação para o objeto em análise e a produção de conhecimento transdisciplinar que ultrapassa a soma do conjunto dessas disciplinas." 
(MARQUES, 2015, p. 196). Na medida em que a ausência de um diálogo efetivo entre as disciplinas acaba por significar também a ausência de comunicação com o mundo, a transdisciplinaridade aparece como uma postura da ciência contemporânea, em contraposição ao especialismo imposto pela Ciência Moderna.

A primeira alusão ao termo Transdisciplinaridade foi feita por Piaget, em 1970, (citado por JAPIASSU, 1976), quando propõe uma etapa superior das relações interdisciplinares que, para além das interações entre pesquisas especializadas, situaria essas ligações no interior de um sistema total, sem fronteiras estabelecidas entre as disciplinas. Naquele momento Piaget afirmara tratar-se de um sonho. A partir sobretudo da década de 1980, surgiram movimentos em vários campos que vêm caracterizando este novo paradigma. Estas correntes possuem uma certa convergência de pensamentos que podem ser percebidas em teorias que estão em discussão atualmente como: indeterminismo, auto-organização, conceito de autopoiesis, teoria da complexidade, teoria de redes, inteligência coletiva, propriedades emergentes e lógica do terceiro incluído, entre outras. (BICALHO; OLIVEIRA, 2005, p.5).

O movimento transdisciplinar pode ser considerado como uma possibilidade de diálogo entre várias ciências e campos do conhecimento. Apesar da necessidade de construção de reflexões e práticas que possam dele dar conta, acaba aparecendo como uma solução para os problemas da sociedade contemporânea. Com a transdisciplinaridade, então, há uma ação desenvolvida em uma perspectiva transgressora

[...] que envolve aquilo que está ao mesmo tempo entre as disciplinas, através das diferentes disciplinas e além de toda e qualquer disciplina. Sua finalidade é a compreensão do mundo atual, na qual um dos imperativos é a unidade de conhecimento. (PINTO, 2007, p. 111).

Tendo em vista o resgate conceitual em torno da disciplinaridade que permeia a CI, percebe-se que para refletir a sua relação inter e transdisciplinar é necessário entender como se deram as transgressões disciplinares nesse campo. A transgressão é entendida como certa “[...] possibilidade de transcendência, forma de romper com as amarras de toda acomodação que apequena, conduzindo a utopias concretas. Transgressão é a consolidação máxima da possibilidade de um novo tempo de educação.” (ESPÍRITO SANTO, 1996, p. 8). A transgressão metodológica, no campo da CI, pode ser entendida, 
então, como a essência de todo trabalho interdisciplinar e transdisciplinar comprometido com uma perspectiva que transcenda, de certa forma, as práticas impostas pela Ciência Moderna.

As transgressões disciplinares, portanto, são tentativas de romper com a prática da ciência monodisciplinar. Definidas dentro de uma categoria que remete à transgressão das leis cientificamente conhecidas, “[...] trata-se de um processo de determinação ignorada, concernente à ocorrência de algo (objeto, força, vetor) que previamente não existia no sistema [...]" (ALMEIDA FILHO, 2005, p. 35).

O estágio inicial da transdisciplinaridade pode ser comparado, então, a uma "transgressão das fronteiras entre as disciplinas", o que a diferencia das abordagens da multidisciplinaridade e da interdisciplinaridade. A prática transdisciplinar pode ser entendida como uma possibilidade de transição no campo da CI (NICOLESCU, 1999).

Inicialmente, a possibilidade de ligar as diversas disciplinas no campo da informação possibilitou o desenho da pluridisciplinaridade como uma abordagem pautada na disciplinaridade, podendo ser entendida como o estudo de uma dada disciplina perante a visão de outras. Apesar de a CI dialogar, metodologicamente, com uma diversidade de disciplinas por meio da pluri e interdisciplinaridade, as finalidades permanecem limitadas à pesquisa disciplinar.

Dada a oportunidade de trocas entre as diversas disciplinas, é possibilitada a CI a difícil arte de transcender. Encaminhar a práxis científica para além da compreensão da unidade do conhecimento comumente adotada, ultrapassando o pensamento clássico monodisciplinar. Com isso, não se desconsidera que "A disciplinaridade, a pluridisciplinaridade, a interdisciplinaridade e a transdisciplinaridade são as quatro flechas de um único e mesmo arco: o do Conhecimento." (NICOLESCU, 1999, p. 54).

Os termos interdisciplinar e transdisciplinar são às vezes tomados como equivalentes, como se fossem da mesma natureza, nem sempre de forma consciente. Mittelstrass e Carrier (2006, p. 246) afirmam que "quando pensada de uma forma realmente séria, a interdisciplinaridade é uma transdisciplinaridade". Guattari (2006, p. 156), ao discorrer sobre os fundamentos ético-políticos da 
interdisciplinaridade, diz preferir chamar transdisciplinaridade a interdisciplinaridade que passa "pela reinvenção permanente da democracia nos diversos estratos do campo social". As duas citações feitas são de textos publicados pela primeira vez em 1990 e 1992, respectivamente, época em que apareceu mais fortemente o termo transdisciplinaridade, o que pode explicar, em parte, as opções igualmente válidas para os autores de utilizarem alternativamente os termos. (BICALHO; OLIVEIRA, 2011, p. 97).

Com a transdisciplinaridade, há uma maior possibilidade da eliminação das fronteiras por meio da superposição e da interpenetração de uma diversidade de metodologias e experiências, tendo em vista que na contemporaneidade é necessário propor metodologias que consigam prever a complexidade que essa transgressão metodológica apresenta. "No projeto transdisciplinar todas as disciplinas são reconstruídas para além de seus próprios limites e, assim, esvaziadas de seus limites convencionais, passam a ter um caráter de abstração." (BICALHO; OLIVEIRA, 2011, p. 96).

Como no caso da disciplinaridade, a pesquisa transdisciplinar não é antagônica, mas complementar à pesquisa pluri e interdisciplinar. A transdisciplinaridade é, no entanto, radicalmente distinta da pluri e da interdisciplinaridade, por sua finalidade: a compreensão do mundo presente, impossível de ser inscrita na pesquisa disciplinar. A finalidade da pluri e da interdisciplinaridade sempre é a pesquisa disciplinar. Se a transdisciplinaridade é tão frequentemente confundida com a inter e a pluridisciplinaridade (como, aliás, a interdisciplinaridade é tão frequentemente confundida com a pluridisciplinaridade), isto se explica em grande parte pelo fato de que todas as três ultrapassam as disciplinas. Esta confusão é muito prejudicial, na medida em que esconde as diferentes finalidades destas três novas abordagens. (NICOLESCU, 1999, p. 54).

As abordagens mencionadas assumem diversas significações ao longo das últimas décadas, mantendo em comum a idéia de que representam movimentos que surgiram em resposta à fragmentação do conhecimento (BICALHO; OLIVEIRA, 2011). O modelo transdisciplinar, nesse processo, assume consequências particularmente importantes perante o estudo da complexidade, com a qual uma diversidade de objetos transdisciplinares respondem "[...] a simplicidade infinita do Sujeito transdisciplinar, da mesma forma que a complexidade terrificante de um único nível de Realidade pode 
significar a simplicidade harmoniosa de um outro nível de Realidade." (NICOLESCU, 1999, p. 66).

\begin{abstract}
A prática da transdisciplinaridade significa "a encarnação, em cada ação, da metodologia transdisciplinar, através de um conjunto de métodos adaptados a cada situação específica", de acordo com Nicolescu (2000, p.129). Uma metodologia geral da transdisciplinaridade não existe, mas sim "uma que se encontra a partir do problema transdisciplinar colocado" (BRANDÃO, 2007, p. 337). Em vista de um problema e um contexto específicos, esses são tratados com os materiais disponíveis, voltados para a resolução do problema e dos saberes em pauta, constituindo uma rede que se adequa ao objeto e não à solução de qualquer problema, explica o referido autor. Dessa forma, muitos métodos são compatíveis com uma única metodologia, formulada de acordo com os pressupostos básicos sobre os quais deve apoiar-se a transdisciplinaridade (níveis de realidade, lógica do terceiro incluído e complexidade); também devem estar de acordo com as novas definições de sujeito e objeto que emergem da metodologia da transdisciplinaridade (NICOLESCU, 2001). (BICALHO; OLIVEIRA, 2011, p. 97).
\end{abstract}

Com o conceito transdisciplinar, novas estruturas de interação entre disciplinas foram, dessa forma, favorecidas no contexto pós-guerra, entre as quais Bicalho e Oliveira (2011) citam os programas de pesquisa em meio ambiente, estudos culturais, estudos da mulher, entre outros. A proposta da transdisciplinaridade é a de caminhar em meio às disciplinas, transpondo as barreiras que costumam impedir seus diálogos com outros campos do conhecimento.

\title{
4 À Guisa de Conclusões
}

O modelo de racionalidade que preside a Ciência Moderna constitui-se a partir da revolução científica, por volta do século XVII, sendo desenvolvido nos séculos seguintes, basicamente, no domínio das ciências naturais. $\mathrm{O}$ avanço do domínio das ciências nos séculos XX e XXI é inegável. Destaca-se, nesse contexto, a constituição da CI como campo científico, porém, que tem encontrado obstáculos, principalmente, no que se refere a uma diversidade de abordagens adotadas no processo de sua constituição.

Tendo em vista os conceitos que alguns autores brasileiros trabalham, realizou-se uma discussão acerca do âmago da questão da sua natureza interdisciplinar, correlacionados com a pluri, multi e, principalmente, com a 
transdisciplinaridade. De modo geral, permanece o interesse pela interdisciplinaridade de forma a redefinir métodos e técnicas de pesquisas, tornando-se necessário a consciência de que os objetos são complexos, já que tem como base os problemas que a contemporaneidade apresenta. Não basta um simples encontro entre as disciplinas, torna-se imperativo derrubar as barreiras que existem entre elas, a fim de que o diálogo realmente aconteça.

$\mathrm{Na}$ atualidade, a CI, então, reflete aspectos conceituais que vão ao encontro da abordagem interdisciplinar, procurando pensar uma possível interação com outras disciplinas. Nesse contexto, a abordagem multidisciplinar, por exemplo, pode ser considerada como uma abordagem que propõe alternativas de pensar e fazer da ciência, disponibilizando formas de investigação científica que atendam às necessidades de compreensão de fatos e fenômenos em toda a sua complexidade.

Todavia, compreende-se que a multidisciplinaridade constitui-se como uma abordagem na qual os especialistas continuam em seus domínios de saber isolados. Nela, a solução de problemas é particionada em vários recortes (objetos), sendo que cada um é abordado por uma especialidade distinta.

À luz das discussões teóricas, percebe-se que a transdisciplinaridade possibilita a articulação entre os saberes das disciplinas e de outras áreas de produção de conhecimento, partindo de perspectivas em oposição ao conhecimento monodisciplinar (conceito que diz respeito a uma só disciplina ou área de conhecimento). Muitas vezes, um problema que a ciência na contemporaneidade apresenta é complexo, não encontrando possibilidade de solução com os saberes existentes, nesse caso, requerendo a transgressão disciplinar. Nesse sentido, a transdisciplinaridade desafia os paradigmas atuais e, portanto, leva em consideração a transgressão metodológica necessária para a abertura de diálogo entre as diversas disciplinas que estão ao seu entorno e as novas questões que a sociedade apresenta.

Por fim, considera-se que entender como se deram as transgressões disciplinares no campo da CI torna-se condição essencial para dar conta de refletir uma relação inter e transdisciplinar necessária à manutenção de uma prática científica em permanente constituição. 


\section{Referências}

ALMEIDA FILHO, Naomar de. Transdisciplinaridade e o Paradigma PósDisciplinar na Saúde. Saúde e Sociedade, São Paulo, v. 14, n. 3, p. 30-50, set./dez. 2005. Disponível em: 〈http://www.scielo.br/pdf/sausoc/v14n3/04.pdf>. Acesso em: 15 mai. 2015.

BICALHO, Lucinéia Maria; OLIVEIRA, Marlene de. Aspectos conceituais da transdiciplinaridade e a pesquisa em Ciência da Informação. Informação \& Sociedade: Estudos, João Pessoa, v. 21, n. 2, p. 87-102, maio/ago. 2011. Disponível em: 〈http://www.ies.ufpb.br/ojs2/index.php/ies/article/view/9746/5964>. Acesso em: 30 ago. 2015.

BICALHO, Lucinéia Maria; OLIVEIRA, Marlene de. Transdisciplinaridade nas ciências: o lugar da Ciência da Informação. ENCONTRO BRASILEIRO DE ESTUDOS DA COMPLEXIDADE, 1., Curitiba, PR, 2005. Anais... Curitiba: IEC, PUC Paraná, UFPR e UFSC, 2005. Disponível em:

$<$ http://cetrans.com.br/artigos/Lucineia_Maria_Bicalho_e_Marlene de_Oliveira .pdf >. Acesso em: 30 ago. 2015.

ESPÍRITO SANTO, Ruy Cézar do. Pedagogia da Transgressão: Um caminho para o autoconhecimento. Campinas: Papirus, 1996.

FRANCELIN, Marivalde Moacir. Conceitos, domínios do saber e fronteiras epistemológicas. Revista Digital de Biblioteconomia e Ciência da Informação, Campinas, v. 8, n. 2, p. 172-165, jan./jun. 2011. Disponível em: < http://periodicos.sbu.unicamp.br/ojs/index.php/rdbci/article/view/1938>. Acesso em: 25 set. 2015.

FREIRE, Gustavo Henrique. Ciência da Informação: temática, histórias e fundamentos. Perspectiva em Ciência da Informação, Belo Horizonte, v. $11 \mathrm{n}$. 1, p. 6-19, jan./abr. 2006.

GOMES, Henriette Ferreira. Interdisciplinaridade e Ciência da Informação: de característica a critério delineador de seu núcleo principal. DataGramaZero - Revista de Ciência da Informação, Rio de Janeiro, v. 2, n. 4, ago. 2001.

JAPIASSÚ, Hilton. Interdisciplinaridade e patologia do saber. Rio de Janeiro: Imago, 1976. 221 p.

JAPIASSÚ, Hilton; MARCONDES, Danilo. Dicionário básico de filosofia. 3 . ed. Rio de Janeiro: Jorge Zahar, 2001.

LE COADIC, Yves-François. A ciência da informação. Brasília: Briquet de Lemos, 2004. 
MARQUES, Márcia. Ação comunicativa e de informação: modelo transdisciplinar para o aprender a aprender. RICI: Revista Ibero-Americana de Ciência da Informação, Brasília, v. 8, n. 2, p. 194 -211, jul./ dez. 2015. Disponível em: <http://periodicos.unb.br/index.php/RICI/article/view/15732>. Acesso em: 29 set. 2015.

MORIN, Edgar. A cabeça bem-feita: repensar a reforma, reformar o pensamento. 8. ed. Rio de Janeiro: Bertrand Brasil, 2003.

NICOLESCU, Basarab. O Manifesto da Transdisciplinaridade. São Paulo: Triom, 1999.

PINHEIRO, Lena Vânia Ribeiro. Campo interdisciplinar da Ciência da Informação: fronteiras remotas e recentes. In: PINHEIRO, Lena Vânia Ribeiro. Ciência da Informação, Ciências Sociais e interdisciplinaridade. Brasília: IBICT, 1999. p.155-182.

PINHEIRO, Lena Vânia Ribeiro. Pilares conceituais para mapeamento do território epistemológico da ciência da informação: disciplinaridade, interdisciplinaridade, transdisciplinaridade e aplicações. In: PINTO, Virgínia Bentes; CAVALCANTE, Lídia Eugênia; SILVA NETO, Casemiro (Orgs.). Ciência da Informação: Abordagens Transdisciplinares, Gêneses e Aplicações. Fortaleza: UFC, 2007. p. 71-104.

PINHEIRO, Lena Vânia Ribeiro; LOUREIRO, José Mauro Matheus. Traçados e limites da ciência da informação. Ciência da Informação, Brasília, v. 24, n. 1, 1995.

PINTO, Virgínia Bentes. Interdisciplinaridade na Ciência da Informação: aplicabilidade sobre a representação indexal. In: PINTO, Virgínia Bentes; CAVALCANTE, Lídia Eugênia; SILVA NETO, Casemiro (Orgs.). Ciência da Informação: Abordagens Transdisciplinares, Gêneses e Aplicações. Fortaleza: UFC, 2007.

POMBO, Olga. Interdisciplinaridade e integração dos saberes. Liinc em Revista, Rio de Janeiro, v. 1, n. 1, p. 13-14, mar. 2005.

SANTOS, Boaventura de Souza. Um discurso sobre as ciências. 7. ed. São Paulo: Cortez, 2010.

SOUZA, Maria da Paixão Neres de. Abordagem inter e transdisciplinar em ciência da informação. In: TOUTAIN, Lídia Maria Batista Brandão (Org.). Para entender a Ciência da Informação. Salvador: EDUFBA, 2007.

TÁLAMO, Maria de Fátima Gonçalves Moreira; SMIT, Johanna Wilhelmina. Ciência da Informação: a transgressão metodológica. In: PINTO, Virgínia Bentes; CAVALCANTE, Lídia Eugênia; SILVA NETO, Casemiro (Orgs.). 
Ciência da Informação: Abordagens Transdisciplinares, Gêneses e Aplicações. Fortaleza: UFC, 2007a.

TÁLAMO, Maria de Fátima Gonçalves Moreira; SMIT, Johanna Wilhelmina. Ciência da Informação: pensamento informacional e integração disciplinar. Brazilian Journal of Information Science, São Paulo, v. 1, n. 1, p. 33-57, jan./jun. 2007b.

\title{
Transgressions in the Information Science field: approaches of a scientific practice in permanent constitution
}

\begin{abstract}
The article presents disciplinary concepts related to the field of information science, as well as it initiates a discussion on the interdisciplinary nature of science crossed by methodological transgression. It reflects about the capacity to interact with other disciplines that cross it, by seeking to get troubleshooting before the composition of its object: information. Therefore, it dialogues with authors such as Le Coadic, Bicalho and Oliveira, Francelin, Japiassú, Marques, Morin; Pinheiro, Tálamo and Smit. Moreover, in order to understand how the disciplinary transgressions works in the information science field, it becomes essential to reflect about the inter relationship, multi and mainly transdisciplinary, necessary to maintain a scientific practice in permanent constitution.
\end{abstract}

Keywords: Information Science. Interdisciplinarity. Transdisciplinarity. Disciplinary transgression.

Recebido em: 29/09/2016

Aceito em: 13/12/2016

\footnotetext{
${ }^{1}$ Santos (2010) utiliza a denominação pós-modernidade para explicar esse processo de transição na atualidade. Neste artigo, dotaremos a denominação contemporaneidade para se referir ao contexto de mudança da sociedade atual.

${ }^{2}$ Discussão compreendida no âmbito do Doutorado Interinstitucional do Programa de PósGraduação em Ciência da Informação (PPGCInf) da Universidade de Brasília (UnB), em parceria com o Grupo de Estudos Educação e Trabalho em Arquivologia e Biblioteconomia (GEETAB) do Departamento de Biblioteconomia da Universidade Federal do Espírito Santo (Ufes).
} 